\title{
COMPARISON OF CORONARY-ARTERY BYPASS SURGERY AND STENTING FOR THE TREATMENT OF MULTIVESSEL DISEASE
}

\author{
Patrick W. Serruys, M.D., Felix Unger, M.D., J. Eduardo Sousa, M.D., Adib Jatene, M.D., \\ Hans J.R.M. Bonnier, M.D., Jacoues P.A.M. Schönberger, M.D., Nigel Buller, M.D., Robert Bonser, M.D., \\ Marcel J.B. van den Brand, M.D., Lex A. van Herwerden, M.D., Marie-Angèle M. Morel, B.Sc., \\ and Ben A. van Hout, Ph.D., for the Arterial Revascularization Therapies Study Group*
}

\begin{abstract}
Background The recent recognition that coronaryartery stenting has improved the short- and long-term outcomes of patients treated with angioplasty has made it necessary to reevaluate the relative benefits of bypass surgery and percutaneous interventions in patients with multivessel disease.

Methods A total of 1205 patients were randomly assigned to undergo stent implantation or bypass surgery when a cardiac surgeon and an interventional cardiologist agreed that the same extent of revascularization could be achieved by either technique. The primary clinical end point was freedom from major adverse cardiac and cerebrovascular events at one year. The costs of hospital resources used were also de-
\end{abstract} termined.

Results At one year, there was no significant difference between the two groups in terms of the rates of death, stroke, or myocardial infarction. Among patients who survived without a stroke or a myocardial infarction, 16.8 percent of those in the stenting group underwent a second revascularization, as compared with 3.5 percent of those in the surgery group. The rate of event-free survival at one year was 73.8 percent among the patients who received stents and 87.8 percent among those who underwent bypass surgery $(\mathrm{P}<0.001$ by the log-rank test). The costs for the initial procedure were $\$ 4,212$ less for patients assigned to stenting than for those assigned to bypass surgery, but this difference was reduced during follow-up because of the increased need for repeated revascularization; after one year, the net difference in favor of stenting was estimated to be $\$ 2,973$ per patient.

Conclusions As measured one year after the procedure, coronary stenting for multivessel disease is less expensive than bypass surgery and offers the same degree of protection against death, stroke, and myocardial infarction. However, stenting is associated with a greater need for repeated revascularization. (N Engl J Med 2001;344:1117-24.)

Copyright $\odot 2001$ Massachusetts Medical Society.

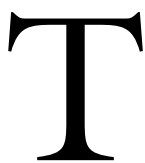

HE latest worldwide survey of coronary revascularization shows that 583,000 coronary-artery bypass operations were performed in 1995. ${ }^{1}$ According to European statistics, the annual rate of use of balloon angioplasty is approximately 739 procedures per million population. ${ }^{2}$ Approximately 60 percent of patients treated with balloon angioplasty or bypass surgery have multivessel disease that could be treated by either pro- cedure. ${ }^{3}$ The most appropriate treatment remains a matter of debate. Earlier studies suggested that patients undergoing either procedure have similar outcomes in terms of survival and rates of myocardial infarction, but patients treated with bypass surgery needed fewer additional interventions. ${ }^{4}$ However, subsequent improvements in both percutaneous and surgical techniques may now limit the validity of any conclusions that have been drawn from the earlier studies.

Reevaluation may be especially important in the case of angioplasty, since several studies show that coronary stenting necessitates fewer repeated revascularization procedures than does angioplasty without stenting. 5,6 Although surgery may still be considered more appropriate than conventional balloon angioplasty for multivessel disease, this may not be the case when stent placement is performed in conjunction with balloon angioplasty. 7,8

Another reason to reevaluate these surgical and percutaneous techniques is the growing concern about the cost of health care. Although stenting may still be less effective than surgery, as indicated by the need for repeated revascularization, its use may result in cost savings. $6,9,10$ Increasingly, the additional effects of new therapies must be weighed against their costs. ${ }^{11-13}$ Therefore, the Arterial Revascularization Therapies Study was designed to compare not only clinical outcomes, but also the costs to the hospital of resources associated with bypass surgery and stenting and the relative cost effectiveness of the procedures.

\section{METHODS}

\section{Study Design}

We conducted a randomized trial comparing coronary bypass surgery with percutaneous transluminal coronary angioplasty and stenting. For each patient, entry into the study required agreement on the part of a surgeon and an interventional cardiologist that an equivalent degree of revascularization could be attained by either approach. Our analysis incorporates data on the clinical efficacy of the procedures, the costs, the cost effectiveness, and the pa-

From the Academisch Ziekenhuis Rotterdam Dijkzigt, Rotterdam, the Netherlands (P.W.S., M.J.B.B., L.A.H.); Klinik fuer Herzchirurgie, Salzburg, Austria (F.U.), Instituto Dante Pazzanese de Cardiologia, São Paulo, Brazil (J.E.S., A.J.); Catharina Ziekenhuis, Eindhoven, the Netherlands (H.J.R.M.B. J.P.A.M.S.); Queen Elizabeth Hospital, Birmingham, United Kingdom (N.B., R.B.); Cardialysis, Rotterdam, the Netherlands (M.-A.M.M.); and the Institute for Medical Technology Assessment, Rotterdam, the Netherlands (B.A.H.). Address reprint requests to Dr. Serruys at the Department of Interventional Cardiology Heart Center, Erasmus University Rotterdam, Dr. Molewaterplein 40, 3015 GD Rotterdam, the Netherlands, or at serruys@ card.azr.nl.

*Participants in the study group are listed in the Appendix. 
tient's quality of life after 30 days and at 1,3 , and 5 years. An extensive description of the study's aims, the selection of patients, the criteria for exclusion, the procedural guidelines, and the administrative structure has been published previously. ${ }^{14}$

\section{Selection of Patients}

Patients who had not previously undergone bypass surgery or angioplasty were eligible for coronary revascularization if they had either stable angina pectoris (Canadian Cardiovascular Society class I, II, III, or IV) ${ }^{15}$ or unstable angina pectoris (Braunwald class IB, IC, IIB, IIC, IIIB, or IIIC) ${ }^{16}$ or if they had silent ischemia and at least two new lesions that were located in different vessels and territories (not including the left main coronary artery) and that were potentially amenable to stent implantation. Patients gave written informed consent and were randomly assigned to a treatment group over the telephone by the central office of the study.

One major epicardial vessel or side branch with total occlusion could be included and targeted, provided that the occlusion had been present for less than one month (according to the clinical history) and that one other major vessel had clinically significant stenosis that was amenable to stenting. Conventional balloon angioplasty was permitted, as a complementary treatment without stent implantation, in vessels between $1.50 \mathrm{~mm}$ and $2.75 \mathrm{~mm}$ in diameter if at least two substantial lesions were targeted for stenting. Each patient had to require more than one stent. Decisions to place stents in lesions at bifurcations, in side branches, or in vessels with fresh thrombi, calcifications, very long obstructions (longer than $20 \mathrm{~mm}$ ), or complex anatomical features were left to the discretion of the operators.

Patients had to have a left ventricular ejection fraction of more than 30 percent, and patients with overt congestive heart failure were excluded..$^{14,17}$ Patients were also excluded if they had a history of a cerebrovascular accident; if they had had transmural myocardial infarction in the previous week; if they had severe hepatic or renal disease, diseased saphenous veins, neutropenia or thrombocytopenia, or an intolerance or contraindication to acetylsalicylic acid or ticlopidine; or if they needed concomitant major surgery (e.g., valve surgery, resection of an aortic or left ventricular aneurysm, carotid endarterectomy, or surgery for an abdominal aortic aneurysm).

\section{End Points}

The primary end point was freedom, for 12 months after randomization, from major adverse cardiac or cerebrovascular events, defined as death; stroke, transient ischemic attacks, and reversible ischemic neurologic deficits ${ }^{14}$; documented nonfatal myocardial infarction; and repeated revascularization by percutaneous intervention or surgery. Deaths from all causes were reported.

In the first seven days after the intervention, a definite diagnosis of myocardial infarction was made if there was documentation of new abnormal $\mathrm{Q}$ waves (according to the Minnesota code) $)^{18}$ and either a ratio of serum creatine kinase $\mathrm{MB}(\mathrm{CK}-\mathrm{MB})$ isoenzyme to total cardiac enzyme that was greater than 0.1 or a $\mathrm{CK}-\mathrm{MB}$ value that was five times the upper limit of normal. Serum creatine kinase and CK-MB isoenzyme concentrations were measured 6,12 , and 18 hours after the intervention. Beginning eight days after the intervention (the length of the hospital stay after surgery), either abnormal $Q$ waves or enzymatic changes were sufficient for a diagnosis of myocardial infarction. This two-part method of defining myocardial infarction was used to eliminate the difficulty of diagnosing a myocardial infarction after surgery. $19,20 \mathrm{~A}$ myocardial infarction was confirmed only after the relevant electrocardiograms had been analyzed by the electrocardiographic core laboratory and adjudicated by a clinical-events committee. All revascularization procedures after the initial intervention and the reasons for them were recorded.

The secondary objective of this study was to compare the two treatment strategies at one year with respect to the following: angina status, use of medications, costs, cost effectiveness, and quality of life; a combined end point of death, myocardial infarction, or stroke; and the rates of death, myocardial infarction, stroke, and revascularization procedures. Events were counted from the time
Table 1. Base-Line Characteristics of the Patients INCLUDED IN THE INTENTION-TO-TREAT ANALYSIS.*

\begin{tabular}{|c|c|c|}
\hline Characteristic & $\begin{array}{l}\text { STENTING } \\
(\mathrm{N}=600)\end{array}$ & $\begin{array}{l}\text { BYPASS } \\
\text { SURGERY } \\
(\mathrm{N}=605)\end{array}$ \\
\hline Male sex (\% of patients) & 77 & 76 \\
\hline \multicolumn{3}{|l|}{ Age (yr) } \\
\hline Mean & $61 \pm 10$ & $61 \pm 9$ \\
\hline Range & $30-83$ & $32-82$ \\
\hline Body-mass index $\dagger$ & $27.2 \pm 3.7$ & $27.4 \pm 3.7$ \\
\hline \multicolumn{3}{|l|}{ Previous conditions ( $\%$ of patients) } \\
\hline Q-wave or non-Q-wave myocardial infarction & 44 & 42 \\
\hline Diabetes mellitus & 19 & 16 \\
\hline Hypertension & 45 & 45 \\
\hline Hypercholesterolemia & 58 & 58 \\
\hline Family history of myocardial infarction & 39 & 42 \\
\hline Peripheral vascular disease & 6 & 5 \\
\hline Chronic obstructive pulmonary disease & 5 & 5 \\
\hline Current smoker (\% of patients) & 28 & 26 \\
\hline Stable angina (\% of patients) $\ddagger$ & 57 & 60 \\
\hline Unstable angina ( $\%$ of patients $) \mathbb{S}$ & 37 & 35 \\
\hline Silent ischemia (\% of patients) & 6 & 5 \\
\hline Ejection fraction $(\%)$ & $61 \pm 12$ & $60 \pm 13$ \\
\hline $\begin{array}{l}\text { No. of segments with stenosis }>50 \% \text { of luminal } \\
\text { diameter }\end{array}$ & $2.83 \pm 1.02$ & $2.80 \pm 1.04$ \\
\hline \multicolumn{3}{|l|}{ Number of diseased vessels (\% of patients) } \\
\hline 1 & 2 & 0 \\
\hline 2 & 68 & 67 \\
\hline 3 & 30 & 33 \\
\hline \multicolumn{3}{|l|}{ Vessel territory with stenosis (\% of patients) } \\
\hline Right coronary artery & 71 & 72 \\
\hline Left anterior descending artery & 90 & 90 \\
\hline Left circumflex artery & 71 & 72 \\
\hline Left main coronary artery $\|$ & 0 & 0 \\
\hline Bifurcation or side branch involved (\% of patients) & 34 & 31 \\
\hline Total occlusion (\% of patients) $\mathbb{I}$ & 3 & 5 \\
\hline
\end{tabular}

*Plus-minus values are means \pm SD.

†The body-mass index is defined as the weight in kilograms divided by the square of the height in meters.

$\ddagger$ Stable angina was defined according to the system of the Canadian Cardiovascular Society. ${ }^{15}$

\$Unstable angina was defined according to the system of Braunwald. ${ }^{16}$

IThe vessel territory and the extent of occlusion involved were assessed by an independent angiographic core laboratory.

Involvement of a left main coronary artery was a violation of the study protocol.

of randomization, whereas clinical status was assessed 1 month, 6 months, and 12 months after a planned intervention.

\section{Costs, Efficacy, and Cost Effectiveness}

The costs that were considered were the direct medical costs to the hospital per patient, calculated as the number of resource units (therapeutic procedure, diagnostic procedure, or device) used multiplied by the cost per unit. The resources included outpatient visits, hospital days, postoperative intensive care, coronary care, nonintensive and noncoronary care, diagnostic tests (e.g., clinical laboratory tests), therapeutic procedures measured in terms of their duration (e.g., angiography and surgery), materials consumed (e.g., balloons, wires, catheters, and stents used in revascularization), medication, and rehabilitation services. Patients were also given a "passport" so that the same data could be recorded if they were treated at other hospitals. Unit costs were estimated before the data were analyzed and the estimates were based on detailed information provided by the Dijkzigt Hospital, Rotterdam, the Netherlands, as reported previously. 6,10 
Table 2. Clinical End Points at One Year, in Descending Order of Severity.*

\begin{tabular}{|c|c|c|c|c|c|}
\hline \multirow[t]{2}{*}{ VARIABLE } & \multicolumn{2}{|c|}{ WORST EVENTt } & \multicolumn{2}{|c|}{ All Events $¥$} & \multirow[t]{3}{*}{$\begin{array}{l}\text { ReLATIVE Risk } \\
(95 \% \mathrm{Cl})\end{array}$} \\
\hline & $\begin{array}{l}\text { STENTING } \\
\text { GROUP } \\
(\mathrm{N}=600)\end{array}$ & $\begin{array}{l}\text { SURGERY } \\
\text { GROUP } \\
(\mathrm{N}=605)\end{array}$ & $\begin{array}{l}\text { STENTING } \\
\text { GROUP } \\
(\mathrm{N}=600)\end{array}$ & $\begin{array}{l}\text { SURGERY } \\
\text { GROUP } \\
(\mathrm{N}=605)\end{array}$ & \\
\hline \multicolumn{5}{|c|}{ number (percent) } & \\
\hline Death & $15(2.5)$ & $17(2.8)$ & $15(2.5)$ & $17(2.8)$ & $0.89(0.45-1.77)$ \\
\hline Cerebrovascular accident $\$$ & $9(1.5)$ & $12(2.0)$ & $10(1.7)$ & $13(2.1)$ & $0.78(0.34-1.76)$ \\
\hline $\begin{array}{l}\text { Myocardial infarction } \\
\text { Q-wave } \\
\text { Non-Q-wave }\end{array}$ & $\begin{array}{r}32(5.3) \\
28(4.7) \\
4(0.7)\end{array}$ & $\begin{array}{r}24(4.0) \\
22(3.6) \\
2(0.3)\end{array}$ & $\begin{array}{r}37(6.2) \\
32(5.3) \\
5(0.8)\end{array}$ & $\begin{array}{r}29(4.8) \\
26(4.3) \\
3(0.5)\end{array}$ & $\begin{array}{l}1.29(0.80-2.06) \\
1.24(0.75-2.06) \\
1.68(0.40-7.00)\end{array}$ \\
\hline $\begin{array}{l}\text { Repeated revascularization } \\
\text { CABG } \\
\text { PTCA }\end{array}$ & $\begin{aligned} 101 & (16.8) \\
28 & (4.7) \\
73 & (12.2)\end{aligned}$ & $\begin{array}{r}21(3.5) \\
3(0.5) \\
18(3.0)\end{array}$ & $\begin{aligned} 126 & (21.0) \\
40 & (6.7) \\
94 & (15.7)\end{aligned}$ & $\begin{array}{r}23(3.8) \\
4(0.7) \\
20(3.3)\end{array}$ & $\begin{array}{r}5.52(3.59-8.49) \\
10.08(3.63-28.01) \\
4.74(2.96-7.58)\end{array}$ \\
\hline Event-free survival $\mathbb{I}$ & $443(73.8)$ & $531(87.8)$ & - & - & - \\
\hline Any event & $157(26.2)$ & $74(12.2)$ & - & - & $2.14(1.66-2.75)$ \\
\hline
\end{tabular}

* One patient in the stenting group had a myocardial infarction while on the waiting list for the procedure; in the surgery group, three patients died while on the waiting list, one patient had a cerebrovascular accident, and four patients had myocardial infarctions. CI denotes confidence interval, CABG coronary-artery bypass grafting, and PTCA percutaneous transluminal coronary angioplasty.

†If a patient required repeated angioplasty and later required coronary-artery bypass grafting, only the worst event $(\mathrm{CABG})$ was counted as an event.

¥If a patient required repeated angioplasty and later required coronary-artery bypass grafting, the total count for "CABG" and "PTCA" at 365 days would reflect both events, not just the worst that occurred, but the count for the general variable "Repeated revascularization" would reflect only one event.

\$In the stenting group, five cerebrovascular accidents were thrombotic, one was hemorrhagic, and the nature of the other four is unknown. In the surgery group, seven were thrombotic, one was hemorrhagic, and the nature of the other five is unknown.

$\mathbb{I} \mathbf{P}<0.001$ by the Wilcoxon rank-sum test.

Efficacy was expressed in terms of the primary end point of event-free survival. The balance between costs and efficacy was expressed in terms of the incremental cost-effectiveness ratio, defined as the additional costs per additional year of survival without a major adverse cardiac or cerebrovascular event. Secondary measures of efficacy were assessed by means of the EuroQol questionnaire regarding the quality of life, on which patients grade their general health status. ${ }^{21}$ The questionnaire comprises five items - mobility, self-care, usual activity, pain or discomfort, and anxiety or depression - each of which may be rated as "no problem," "moderate problem," or "severe problem." These ratings were then summarized (EuroQol summary) after being weighted to account for differences in the importance of the various items to the patient. ${ }^{21}$ The questionnaire also includes a visual-analogue scale (EuroQol thermometer) for patients to use in rating their overall status from 0 ("worst" imaginable health) to 100 ("best" imaginable health).

\section{Statistical Analysis}

A total of 600 patients in each of the two groups was required for the study to be able to reject the null hypothesis that at one year the difference in the frequency of major adverse cardiac and cerebrovascular events (event-free survival) in favor of bypass surgery would not exceed 7 percentage points. With the actual sample size, the study achieved a power of 92 percent with the assumption of a two-sided type I error level $(\alpha)$ of 0.05 .

Continuous variables were estimated as means \pm SD and compared with use of Student's unpaired t-test. Fisher's exact test was used for categorical variables with nominal scales and the Wilcoxon or Mann-Whitney rank-sum test for those with ordinal scales. Discrete variables were reported as counts and percentages and were compared in terms of relative risks (for the surgery group versus the stenting group) with 95 percent confidence intervals, calculated according to the formula of Greenland and Robins. ${ }^{22}$ All analyses were based on the intention-to-treat principle, and statistical tests were two-tailed.

Event-free survival was estimated by the Kaplan-Meier method, and differences were assessed by means of the log-rank test. A multivariate logistic-regression model was created with the use of baseline clinical and angiographic characteristics and procedure-related variables (including the method of revascularization - i.e., stenting or surgery) in order to identify independent predictors of the primary end point (event-free survival at one year).

Expectations about costs and cost effectiveness have been reported previously. ${ }^{14}$ In that report, incremental cost-effectiveness ratios were expressed with the use of Fieller's approximation (with 95 percent confidence intervals). ${ }^{23}$

\section{RESULTS}

\section{Characteristics and Treatment of the Patients}

Between April 1997 and June 1998, 1205 patients at 67 participating centers were randomly assigned to undergo stent implantation (600 patients) or bypass surgery ( 605 patients). Table 1 presents their base-line demographic and angiographic characteristics. Five patients, one assigned to stenting and four assigned to surgery, did not undergo coronary revascularization and instead continued to receive pharmacologic treatment. The average interval between randomization and treatment was $27 \pm 39$ days (range, 0 to 362 ) for 
patients in the surgery group and $11 \pm 16$ days (range, 0 to 173) for patients in the stenting group. Three patients died while waiting for surgery. Six patients randomly assigned to stent implantation were instead treated surgically, and 19 patients randomly assigned to bypass surgery were instead treated with stent implantation. During the initial hospital stay, after complicated or unsatisfactory angioplasty procedures, 14 patients assigned to stent implantation underwent bypass surgery, 3 urgently and 11 electively. Conversely, two patients in the surgical group underwent angioplasty during their hospital stay. A total of 99 percent of the patients in the stenting group (593 patients) and 96 percent of those in the surgery group ( 579 patients) received the assigned treatment.

\section{Assessment of Revascularization and Postprocedural Enzyme Levels}

Among the patients in the stenting group, a mean $( \pm S D)$ of $2.8 \pm 1.0$ lesions with stenosis of more than 50 percent of the luminal diameter were detected on the diagnostic angiogram, and 2.6 \pm 1.1 lesions had stents placed ( 89 percent) or were treated with balloon angioplasty alone (11 percent). However, in 15.2 percent of the patients in the stenting group, one or more of the target lesions did not receive the intended treatment, whereas in 10.2 percent of these patients procedures were performed that were not initially planned. In the surgery group, a mean of $2.8 \pm 1.0$ lesions were found per patient, and a mean of $2.6 \pm 1.0$ anastomoses were performed with the use of a mean of $2.5 \pm 0.7$ conduits. In 4.5 percent of patients in this group, however, the intended surgical procedure was not performed. In 93 percent of the patients in the surgery group, at least one arterial conduit was used; in 95 percent of these patients, the left anterior descending artery was revascularized with an arterial conduit. In the stenting group, the average total length of the stents implanted was $47.5 \pm 21.8 \mathrm{~mm}$ per patient; 27 percent of the individual stents were longer than $15 \mathrm{~mm}$. Bypass surgery required an average of $234 \pm 74$ minutes, whereas stenting took an average of $98 \pm 52$ minutes $(\mathrm{P}<0.001)$.

In the first 18 hours after the intervention, abnormal CK-MB levels were observed in 61 percent of the patients in the surgery group and 31 percent of the patients in the stenting group. Creatine kinase values more than five times the upper limit of normal were found in 12.6 percent of the patients in the surgery group and 6.2 percent of the patients in the stenting group $(\mathrm{P}<0.001)$.

\section{Clinical Outcomes}

In the stenting group, 40 percent of the major adverse events that occurred in the first 30 days after intervention were due to stent thrombosis. This complication occurred in 1.1 percent of the stented le-

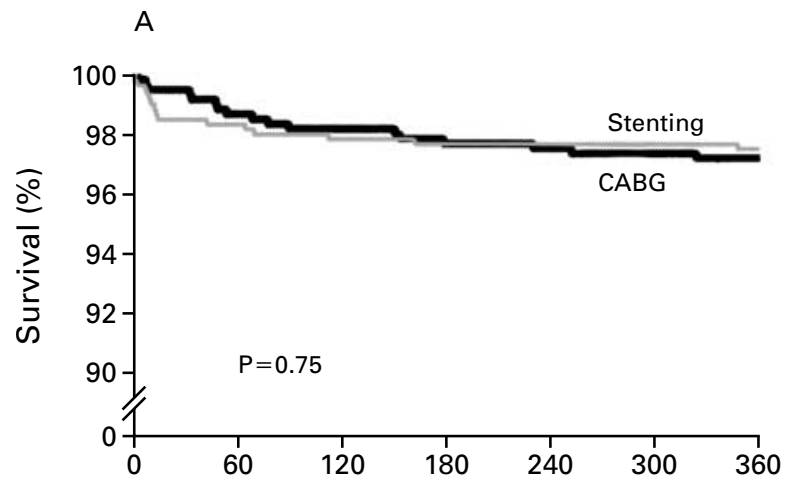

B

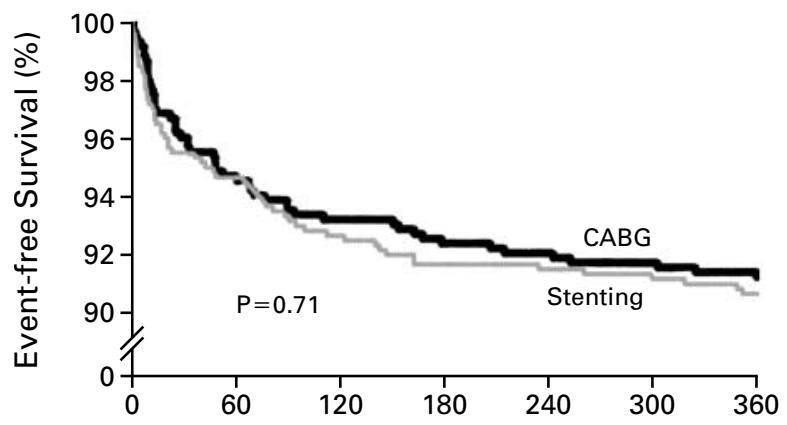

C

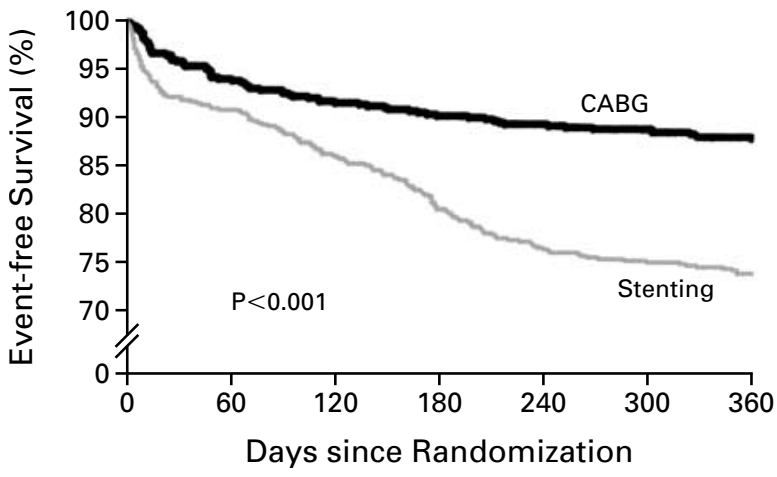

Figure 1. Actuarial Survival (Panel A), Kaplan-Meier Estimates of Survival without Myocardial Infarction or Cerebrovascular Events (Panel B), and Kaplan-Meier Estimates of Survival without Cerebrovascular Events, Myocardial Infarction, or Repeated Revascularization (Panel C) among Patients Assigned to Undergo Stenting, as Compared with Those Assigned to Undergo Coronary-Artery Bypass Grafting (CABG).

There was a significant difference between the groups in survival without cerebrovascular events, myocardial infarction, or repeated revascularization ( $\mathrm{P}<0.001$ by the log-rank test). 
sions but in 2.8 percent of the patients. The frequency of major adverse cardiac and cerebrovascular events and the number of patients in whom each type of event occurred are shown in Table 2. One of these events occurred in 157 of the 600 patients assigned to stent implantation (26.2 percent), as compared with 74 of the 605 patients assigned to bypass surgery (12.2 percent; relative risk, $2.14 ; 95$ percent confidence interval, 1.66 to 2.75 ). Similar numbers of patients in the two groups were alive at one year and had not had a stroke or a myocardial infarction (90.7 percent in the stenting group and 91.2 percent in the surgery group; relative risk of death, stroke, or nonfatal myocardial infarction, 1.07; 95 percent confidence interval, 0.75 to 1.52 ). Of these patients, 16.8 percent in the stenting group and 3.5 percent in the surgery group underwent repeated revascularization (an absolute difference of 13.3 percent). Overall, 21.0 percent of the patients in the stenting group underwent additional revascularization, as compared with 3.8 percent of those in the surgery group (relative risk, 5.52; 95 percent confidence interval, 3.59 to 8.49 ). The different clinical outcomes are illustrated by the Kaplan-Meier estimates of event-free survival in the two original groups and among patients who survived for one year without a stroke or a myocardial infarction (Fig. 1). The better outcome at one year for the patients in the surgery group was also reflected in a significantly higher proportion of patients without angina ( 90 percent after bypass surgery vs. 79 percent after stenting) and a lower rate of use of antianginal medications (Table 3 ).

Multivariate Cox regression analysis in this trial showed that an elevated level of CK-MB was the main predictor of outcome in the surgery group, whereas the presence of diabetes mellitus was the key predictor of outcome in the stenting group.

\section{Quality of Life}

Throughout the 12-month period of observation, more patients were free of angina after bypass surgery than after stenting (Table 3 ). The data from the self-rated EuroQol questionnaire indicated a significantly better quality of life with stenting after 1 month, no difference after 6 months, and a slight difference in favor of surgery after 12 months. The difference at 12 months was attributable to significant differences in the ratings for "usual activity" and "anxiety or depression" and a nonsignificant difference in ratings for "mobility."

\section{Costs and Cost Effectiveness}

As Table 4 shows, the total costs of bypass surgery $(\$ 10,653)$ were significantly greater than those of stenting $(\$ 6,441)$. The difference was due primarily to the differences in the duration of the procedures and the length of the hospital stay. The initial difference of $\$ 4,212$ was later reduced because patients in the stenting group required more repeated revascularizations. Thus, the net difference in favor of stenting had decreased to $\$ 2,973$ by one year. Had a policy of performing elective bypass surgery rather than angioplasty and stenting been applied to every patient enrolled in the trial, the additional costs at one year would have been approximately $\$ 21,329$ per additional patient who survived event-free.

Table 3. Status with Respect to Angina and Medication Use and Quality of Life among Surviving Patients. *

VARIABLE

Free of angina (\%)

Free of antianginal medication (\%)

Free of angina and antianginal medication $(\%)$

EuroQol thermometer†

EuroQol summarył

EuroQol domain

Mobility

Self-care

Usual activity

Pain or discomfort

Anxiety or depression

\begin{tabular}{cc}
\multicolumn{2}{c}{ BASE LINE } \\
STENTING \\
GROURG & GROUP
\end{tabular}

$\begin{array}{ll}0 & 0 \\ 7.5 & 4.6\end{array}$

0

$58 \pm 19 \quad 59 \pm 18$

$69 \pm 20 \quad 68 \pm 20$

$4.1 \pm 6.0 \quad 4.0 \pm 5.9$

$1.6 \pm 4.1 \quad 1.5 \pm 3.9$

$2.9 \pm 3.0 \quad 2.9 \pm 3.0$

$10.9 \pm 9.2 \quad 11.1 \pm 9.5$

$\begin{array}{rr}4.8 \pm 6.0 & 5.2 \pm 6.8\end{array}$

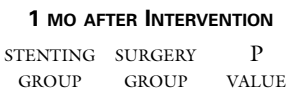

$\begin{array}{ccc}\text { GROUP } & \text { GROUP VALUE }\end{array}$

$87.2 \quad 95.5<0.001$

$16.4 \quad 29.4<0.001$

$14.928 .6<0.001$

$75 \pm 16 \quad 71 \pm 16<0.001$

$84 \pm 16 \quad 78 \pm 17<0.001$

$\begin{array}{lll}1.5 \pm 3.3 & 1.5 \pm 3.3 \quad 0.94\end{array}$

$0.4 \pm 1.9 \quad 1.1 \pm 3.4<0.001$

$1.3 \pm 2.2 \quad 2.5 \pm 2.7<0.001$

$4.7 \pm 6.8 \quad 8.0 \pm 7.3<0.001$

$\begin{array}{llr}3.0 \pm 4.8 & 2.7 \pm 5.1 & 0.10\end{array}$
6 MO AFTER INTERVENTION

STENTING SURGERY P

GROUP GROUP VALUE

$\begin{array}{lll}75.5 & 92.7<0.001\end{array}$

$18.6 \quad 39.0<0.001$

$14.636 .3<0.001$

$78 \pm 15 \quad 78 \pm 15 \quad 0.62$

$86 \pm 16 \quad 86 \pm 15 \quad 0.46$

$1.4 \pm 3.3 \quad 1.1 \pm 2.5 \quad 0.06$

$0.4 \pm 1.9 \quad 0.2 \pm 1.6 \quad 0.10$

$1.0 \pm 1.8 \quad 0.8 \pm 1.8 \quad 0.12$

$\begin{array}{lll}4.8 \pm 7.2 & 5.1 \pm 6.8 & 0.28\end{array}$

$\begin{array}{lll}2.5 \pm 4.3 & 2.3 \pm 4.1 & 0.45\end{array}$
12 MO AFTER INTERVENTION

STENTING SURGERY P

GROUP GROUP VALUE

$78.9 \quad 89.5<0.001$

$21.1 \quad 41.5<0.001$

$19.1 \quad 38.4<0.001$

$78 \pm 15 \quad 80 \pm 15 \quad 0.11$

$86 \pm 16 \quad 87 \pm 16 \quad 0.24$

$1.4 \pm 2.8 \quad 1.1 \pm 2.8 \quad 0.05$

$0.4 \pm 2.1 \quad 0.4 \pm 2.5 \quad 0.53$

$1.0 \pm 1.9 \quad 0.8 \pm 1.8 \quad 0.01$

$\begin{array}{lll}4.4 \pm 7.1 & 4.6 \pm 7.4 & 0.82\end{array}$

$\begin{array}{lll}2.5 \pm 4.5 & 2.0 \pm 4.1 & 0.04\end{array}$

*Plus-minus values are means \pm SD. High scores on the EuroQol thermometer and the EuroQol summary indicate a good quality of life, whereas low scores on the other five items - mobility, self-care, usual activity, pain or discomfort, and anxiety or depression — reflect a favorable assessment of each individual component of the quality of life.

†Respondents rate their overall health status using a $20-\mathrm{cm}$ visual-analogue scale. This scale, which is similar to a thermometer, is marked 100 at the top (best imaginable state of health) and 0 at the bottom (worst imaginable state of health).

¥Information elicited on the five EuroQol domains is converted into a single EuroQol summary (range, 0 to 100 ) after the individual scores have been weighted to account for differences in the importance of the various domains to the patient. 


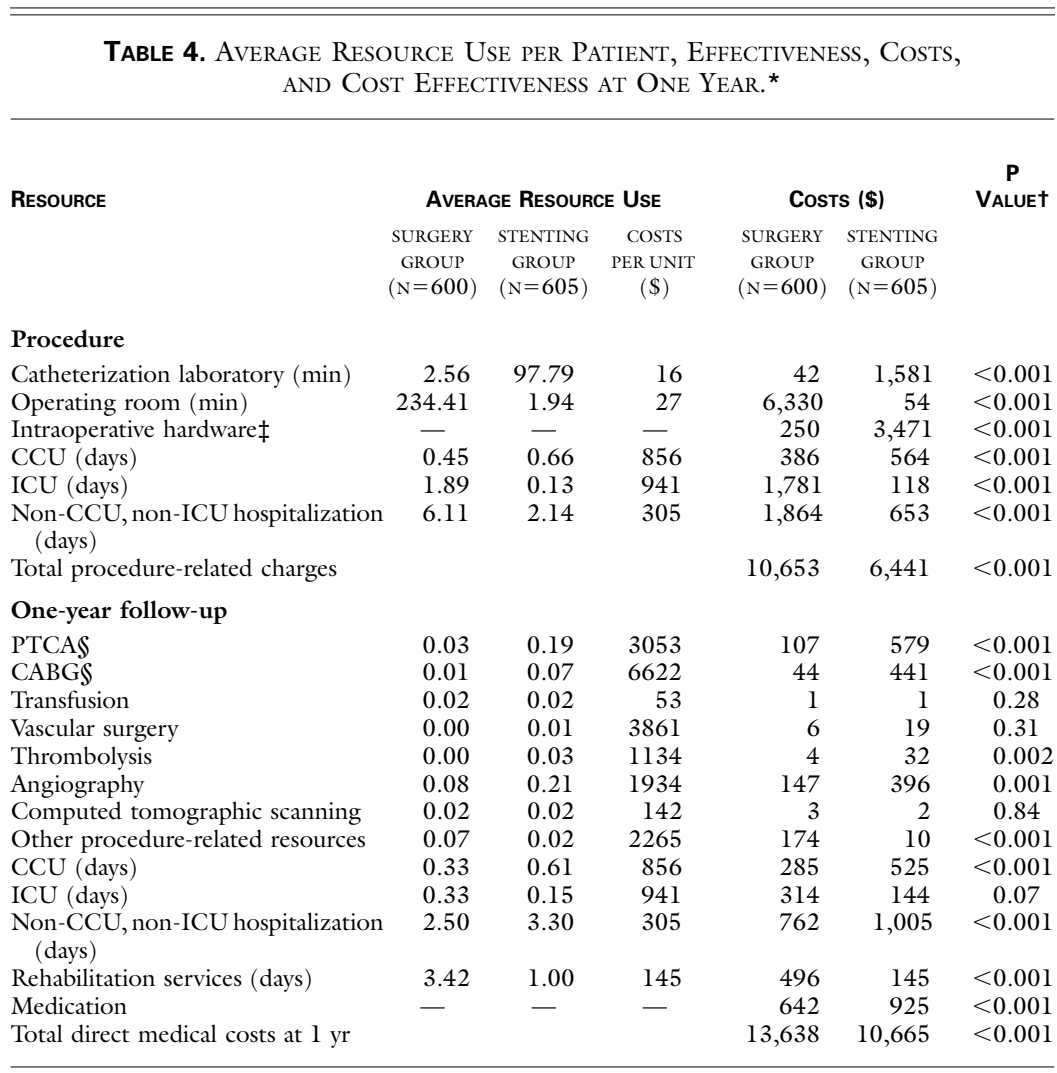

* The costs per unit have been rounded in the calculation of the average. CCU denotes coronary care unit, ICU intensive care unit, PTCA percutaneous transluminal coronary angioplasty, and CABG coronary-artery bypass grafting.

$\dagger P$ values were calculated with use of the Mann-Whitney rank-sum test.

$\ddagger$ Intraoperative hardware includes guiding catheters, guide wires, balloons, stents, atherectomy devices and laser catheters, Doppler and intravascular catheters, cardiopulmonary support and intra-aortic balloon-pump catheters, and endarterectomy devices. Abciximab, as an adjunctive intraoperative drug, was administered to 18 patients in the stenting group.

\$The costs for either a target or a nontarget vessel are included.

\section{DISCUSSION}

We found no significant difference between the two treatment groups in the combined rate of death, stroke, and myocardial infarction; a difference of 17.2 percentage points in the rate of repeated revascularization in favor of surgery; and lower costs (by $\$ 2,973$ ) at 12 months in favor of coronary stenting. Our results present physicians with a dilemma. Angioplasty with stenting is less invasive than surgery and is associated with a faster recovery and a better quality of life one month after the intervention. Bypass surgery is associated with a lower incidence of angina, less need for antianginal medications, and fewer repeated interventions in the first year after the procedure. A decision to perform bypass surgery will probably cost approximately $\$ 3,000$ more than a decision to perform angioplasty with stenting, but it may result in 14 additional patients with event-free survival per 100 treated patients, as suggested by the differ- ence of 14 percentage points in event-free survival in our study. As compared with stenting, in other words, it would be necessary to perform bypass surgery in seven patients in order for one additional patient to survive for one year without adverse events $(1.0 \div 0.14=$ $7.14)$; doing so would cost approximately $\$ 21,000$ - an incremental cost-effectiveness ratio of $\$ 21,000$ per additional patient who survives event-free. These figures are substantially more favorable than the costeffectiveness estimates for the use of abciximab in patients who are undergoing angioplasty ${ }^{24}$ or for the use of primary balloon angioplasty in patients who have had a myocardial infarction. ${ }^{25}$

The interval between randomization and treatment was approximately three times longer for the patients in the surgery group than for those in the stenting group, and eight major adverse cardiac events occurred in patients assigned to bypass surgery before they had undergone surgery, as compared with one such event 
in a patient assigned to stent implantation. These delays and events handicapped the late follow-up of the patients in the surgery group. There are reports that delays caused by waiting lists for cardiac surgery may pose risks. ${ }^{26-28}$

The trial was initiated in April 1997, and one-year follow-up data were available in August 1999. Since practice evolves continuously, it is relevant to consider the differences between the techniques used in this study and newly developed techniques for coronary revascularization that may affect future practice, such as surgery without cardiopulmonary bypass and new, minimally invasive approaches. ${ }^{29-34}$ Conversely, the 2.8 percent stent thrombosis rate per patient might have been prevented by platelet glycoprotein IIb/IIIa receptor blockade 35 or use of a heparin-coated stent. ${ }^{6,36,37}$ Furthermore, in 30 percent of the patients with stents, some release of CK-MB was documented; the use of glycoprotein IIb/IIIa inhibitors might have reduced this rate of enzyme release by 50 percent.

The observation that CK-MB enzyme release was the major predictor of clinical outcome in the surgery group, whereas the presence of diabetes mellitus was the key predictor in the stenting group, will further fuel the debate regarding the prognostic and pathophysiological significance of cardiac-enzyme release during surgical revascularization, but it corroborates the findings of the Bypass Angioplasty Revascularization Investigation with respect to the adverse clinical effects of diabetes in patients treated by percutaneous intervention. ${ }^{38}$

Although surgery remains the most effective method of revascularization for multivessel disease, our findings tip the scales of cost effectiveness in favor of the percutaneous approach by demonstrating a substantial reduction in the difference between the outcomes of the procedures. However, "cost" must be defined from the perspective of society as a whole, and each patient's preference must be considered in making individual decisions. Although the percutaneous approach offers the same degree of protection against death and cardiac or cerebrovascular events as surgery and is generally perceived by patients as less invasive, the possible need for further revascularization after an initial percutaneous treatment has to be weighed by the patient and his or her physician in choosing an approach.

Supported by Cordis, a Johnson \& Johnson company.

We are indebted to Dr. Brian Firth, Paul Marshall, and Dr. Robert Pigache for their careful review of the manuscript and for their constructive comments.

\section{APPENDIX}

This study was conducted under the auspices of the European Academy of Sciences and Arts. Patron: Jacques Santer, former president, European Commission in Brussels. Safety and data monitoring committee: S. Pocock,
T. Ryan, K. Taylor; board of governors: M. Woodall, B. Firth, F. Unger, P.W. Serruys, P.G. Hugenholtz; executive steering committee: P.W. Serruys (chair), F. Unger (cochair), L. van Herwerden, F. Mohr, J. Cremer, G. Petterson, R. Simon, W. Wijns, H. Bonnier, A. Colombo, M.-C. Morice, O. Madonna, G.-A. van Es; critical-events committee: J.J. Bredee, O. Hess, W. Morshuis, W. Wijns; angiographic committee: M. van den Brand, B. Rensing, C. van de Wiel; cardialysis data coordinating center and electrocardiography core laboratory (Rotterdam): H. Hennessey, A.-M. Hoogenboom, M. Kuypers. M.-A. Morel, V. de Valk, W. Lindeboom; clinical data monitoring: I. Kuit (Parexel); health economics analysis: B. van Hout.

The following investigators participated in the study (the numbers in parentheses indicate the number of patients enrolled by each team): Brazil: J.E. Sousa, A. Jatene (66); E. Ribeiro, E. Buffolo (26); the Netherlands: H.J.R.M. Bonnier, J.P.A.M. Schönberger (61); P.W. Serruys, L. van Herwerden (47); P.C.H. Roose, T.R. van Geldorp (39); H. Suryapranata, M. Haalebos (27); F. Kiemeney, L. Eysmann (17); F.W.H.M. Bär, K. Prenger (15); A.J. van Boven, P.W. Boonstra (14); H. Gehlmann, S. Singh (7); K. Koch, B.A.J. de Mol (2); United Kingdom: N. Buller, R. Bonser (54); M.T. Rothman, R. Balcon, J. Wright (26); C. Ilsley, M. Yacoub (19); D. Cumberland, F. Ciulli, G. Cooper (16); K. Dawkins, S. Livesey (16); Belgium: V. Legrand, R. Limet (47); W. Wijns, F. Wellens (26); P. van den Heuvel, C. van Cauwelaert (21); M. Vrolix, G. Fransen (17); P. Materne, G. de Koster (17); Y. Taeymans, G. van Nooten (16); E. Schroeder, J.C. Schoevaerdts (9); C. Hanet, R. Dion (5); M. Vandormael, P. Bettendorf (4); Canada: R. Carere, S. Lichtenstein (46); I. Penn, G.F.O. Tyers (20); L. Bilodeau, M. Carrier (17); Germany: G. Schuler, F.W. Mohr (43); R. Simon, D. Regensburger (25); W. Rutsch, W. Konertz (11); P. Hanrath, B. Messmer (10); B. Lösse, M.J. Polonius (7); D.C. Gulba, B. Schübel (4); R. Erbel, M. Haude, J.C. Reidemeister (3); S. Nikol, B. Reichart (2); A. Schömig, H. Meisner, K. Holper (1); Spain: C. Macaya, J.L. Castañon (32); F. Fernandez-Avilès, J. Herreros Gonzáles (28); A. Betriu, J.L. Pomar (14); Austria: G. Heyer, F. Unger (30); P. Probst, E. Wolner, G. Laufer (11); Israel: R. Beyar, S. Milo (25); C. Lotan, G. Merin (10); S. Braun, R. Mor (10); D. Tzivoni, D. Bitran (8); Ireland: P. Crean, E. McGovern (22); Denmark: T. Toftegaard Nielsen, P. Kildeberg Paulsen (18); K. Saunamäki, K. Sander-Jensen (13); Portugal: R. Seabra-Gomes, J. Queiróz E Melo (17); V. Gama Ribeiro, M.D.M.S. Guerreiro (13); Argentina: H.F. Londero, V. Caramutti (16); J. Belardi, D. Navia (3); Switzerland: M. Pieper, D. Maass (16); J.J. Goy, L.K. von Segesser (7); T. Lüscher, M. Turina (6); Australia: G.I.C. Nelson, D. Marshman (15); J.H.N. Bett, P. Tesar (11); Greece: V. Voudris, G. Stavridis (13); France: J.L. Dubois-Rande, D. Loisance (11); M.C. Morice, P. Donzeau-Gouge (9); Italy: G. Binaghi, G. Tarelli (11); G. Piovaccari, C. Marrozzini, G. Marinelli (10); A. Salvi, L. Dreas, B. Branchini (8); A. Colombo, C. Santoli (6); I. Sheiban, O. Alfieri (6); New Zealand: J. Ormiston, P. Ruygrok, A. Kerr (3).

\section{REFERENCES}

1. Unger F. Worldwide survey on coronary interventions 1995: report of the European Heart Academy of Sciences and ARTS. Cor Eur 1999;7:128-46.

2. Idem. Cardiac interventions in Europe 1997: coronary revascularization procedures and open heart surgery. Cor Eur 1999;7:177-86.

3. Rigter H, Meijler AP, McDonnell J, Scholma JK, Bernstein SJ. Indications for coronary revascularisation: a Dutch perspective. Heart 1997;77: 211-8.

4. Pocock SJ, Henderson RA, Rickards AF, et al. Meta-analysis of randomised trials comparing coronary angioplasty with bypass surgery. Lancet 1995;346:1184-9.

5. Versaci F, Gaspardone A, Tomai F, Crea F, Chiariello L, Gioffrè PA. A comparison of coronary-artery stenting with angioplasty for isolated stenosis of the proximal left anterior descending coronary artery. N Engl J Med 1997;336:817-22.

6. Serruys PW, van Hout B, Bonnier H, et al. Randomised comparison of implantation of heparin-coated stents with balloon angioplasty in selected patients with coronary artery disease. Lancet 1998;352:673-81. [Erratum, Lancet 1998;352:1478.]

7. Eeckhout E, Wijns W, Meier B, Goy JJ. Indications for intracoronary stent placement: the European view. Eur Heart J 1999;20:1014-9.

8. Malenka DJ, O'Connor GT. The Northern New England Cardiovascular Disease Study Group: a regional collaborative effort for continuous quality improvement in cardiovascular disease. Jt Comm J Qual Improv 1998;24:594-600.

9. Cohen DJ, Breall JA, Ho KK, et al. Evaluating the potential cost-effectiveness of stenting as a treatment for symptomatic single-vessel coronary disease: use of a decision-analytic model. Circulation 1994;89:1859-74. 10. van den Brand $M$, van Halem C, van den Brink F, et al. Comparison of costs of percutaneous transluminal coronary angioplasty and coronary bypass surgery for patients with angina pectoris. Eur Heart J 1990;11:765-71.

11. Hlatky MA, Rogers WJ, Johnstone I, et al. Medical care costs and 
quality of life after randomization to coronary angioplasty or coronary bypass surgery. N Engl J Med 1997;336:92-9.

12. Sculpher MJ, Seed $P$, Henderson RA, et al. Health service costs of coronary angioplasty and coronary artery bypass surgery: the Randomised Intervention Treatment of Angina (RITA) trial. Lancet 1994;344:927-30. 13. van Hout BA, Goes ES, Grijseels EW, van Ufford MA. Economic evaluation in the field of cardiology: theory and practice. Prog Cardiovasc Dis 1999; $42: 167-73$

14. Serruys PW, Van Hout BA, Van den Brand MJB, et al. The ARTS (Arterial Revascularization Therapies Study): background, goals and methods Int J Cardiovasc Interv 1999;2:41-50.

15. Campeau L. Grading of angina pectoris. Circulation 1976;54:522-3.

16. Braunwald E. Unstable angina: a classification. Circulation 1989;80:

410-4.

17. Protocol for Bypass Angioplasty Revascularization Investigation. Circulation 1991;84:Suppl V:V-2-V-27.

18. Edlavitch SA, Crow R, Burke GL, Baxter J. Secular trends in Q wave and non-Q wave acute myocardial infarction: the Minnesota Heart Survey. Circulation 1991;83:492-503.

19. Hodakowski GT, Craver JM, Jones EL, King SB III, Guyton RA. Clinical significance of perioperative $\mathrm{Q}$-wave myocardial infarction: the Emory Angioplasty versus Surgery Trial. J Thorac Cardiovasc Surg 1996; 112:1447-54

20. Califf RM, Abdelmeguid AE, Kuntz RE, et al. Myonecrosis after revascularization procedures. J Am Coll Cardiol 1998;31:24l-51.

21. Dolan P. Modeling valuations for EuroQol health states. Med Care 1997;35:1095-108

22. Greenland S, Robins JM. Estimation of a common effect parameter from sparse follow-up data. Biometrics 1985;41:55-68.

23. Cox DR. Fieller's theorem and a generalization. Biometrika 1967;54: 567-72.

24. Topol EJ, Mark DB, Lincoff AM, et al. Outcomes at 1 year and economic implications of platelet glycoprotein IIb/IIIa blockade in patients undergoing coronary stenting: results from a multicentre randomised trial. Lancet 1999;354:2019-24. [Erratum, Lancet 2000;355:1104.]

25. Lieu TA, Gurley RJ, Lundstrom RJ, et al. Projected cost-effectiveness of primary angioplasty for acute myocardial infarction. J Am Coll Cardiol 1997;30:1741-50.

26. Bernstein SJ, Rigter $\mathrm{H}$, Brorsson $\mathrm{B}$, et al. Waiting for coronary revascularization: a comparison between New York State, the Netherlands and Sweden. Health Policy 1997;42:15-27.
27. Teo KK, Spoor M, Pressey T, et al. Impact of managed waiting for coronary artery bypass graft surgery on patients' perceived quality of life. Circulation 1998;Suppl II:II-29-II-34.

28. Jackson NW, Doogue MP, Elliott JM. Priority points and cardiac events while waiting for coronary bypass surgery. Heart 1999;81:367-73. 29. Moshkovitz Y, Lusky A, Mohr R. Coronary artery bypass without cardiopulmonary bypass: analysis of short-term and mid-term outcome in 220 patients. J Thorac Cardiovasc Surg 1995;110:979-87.

30. Borst C, Jansen EW, Tulleken CA, et al. Coronary artery bypass grafting without cardiopulmonary bypass and without interruption of native coronary flow using a novel anastomosis site restraining device ("Octopus"). J Am Coll Cardiol 1996;27:1356-64.

31. Calafiore AM, Di Giammarco G, Teodori G, et al. Midterm results after minimally invasive coronary surgery. J Thorac Cardiovasc Surg 1998; 115:763-71

32. Benetti F, Mariani MA, Sani G, et al. Video-assisted minimally invasive coronary operations without cardiopulmonary bypass: a multicenter study. J Thorac Cardiovasc Surg 1996;112:1478-84.

33. Gu YJ, Mariani MA, van Oeveren W, Grandjean JG, Boonstra PW. Reduction of the inflammatory response in patients undergoing minimally invasive coronary artery bypass grafting. Ann Thorac Surg 1998;65:420-

34. Bergsma TM, Grandjean JG, Voors AA, Boonstra PW, den Heyer P, Ebels $\mathrm{T}$. Low recurrence of angina pectoris after coronary artery bypass graft surgery with bilateral internal thoracic and right gastroepiploic arteries. Circulation 1998;97:2402-5.

35. Randomised placebo-controlled and balloon-angioplasty-controlled trial to assess safety of coronary stenting with use of platelet glycoproteinIIb/IIIa blockade. Lancet 1998;352:87-92.

36. Grines CL, Cox DA, Stone GW, et al. Coronary angioplasty with or without stent implantation for acute myocardial infarction. N Engl J Med 1999;341:1949-56.

37. Buller CE, Dzavik V, Carere RG, et al. Primary stenting versus balloon angioplasty in occluded coronary arteries: the Total Occlusion Study of Canada (TOSCA). Circulation 1999;100:236-42.

38. Detre KM, Guo P, Holubkov R, et al. Coronary revascularization in diabetic patients: a comparison of the randomized and observational com ponents of the Bypass Angioplasty Revascularization Investigation (BARI). Circulation 1999;99:633-40.

Copyright (C) 2001 Massachusetts Medical Society. 